RELATO DE CASO

\title{
Sarcoma de Kaposi em membros inferiores: relato de caso
}

\author{
Kaposi sarcoma in the lower limbs: case report \\ Jorge Agle Kalil', Marco Antonio Caldas Jovino², Francine Papaiordanou³, Marcelo Arriaga², Marcelo Augusto Fontenelle Ribeiro $\mathrm{rr}^{4}$
}

\begin{abstract}
Resumo
O sarcoma de Kaposi é uma neoplasia angioproliferativa maligna que na maioria das vezes se restringe à pele e ao tecido subcutâneo; porém, pode aparecer de forma mais agressiva, atingindo a cavidade oral, o trato gastrointestinal e os pulmões (sarcoma de Kaposi visceral). É classificado com quatro variantes clínco-epidemiológicas: clássica, endêmica, iatrogênica e epidêmica, todas associadas ao herpes vírus humano tipo 8. O objetivo desta publicação foi relatar um caso raro de sarcoma de Kaposi em paciente idosa imunossuprimida, não relacionado à síndrome da imunodeficiência adquirida, que evoluiu de forma desfavorável em um período de cinco meses a partir do aparecimento de lesões bolhosas hemáticas e necróticas que, posteriormente, progrediram com intensa exsudação local, desidratação, insuficiência renal e piora do estado geral, evoluindo então a óbito, tendo como causa mortis a falência de múltiplos órgãos.
\end{abstract}

Palavras-chave: Sarcoma de Kaposi; herpesvirus humano 8; neoplasias.

\begin{abstract}
The Kaposi sarcoma is an angio-proliferative malignant neoplasm that mostly affects the skin and subcutaneous tissue, although it can present in a more aggressive form, involving the oral cavity, lungs and gastrointestinal tract (visceral Kaposi sarcoma). It is classified into 4 clinical-epidemiological types: classic, endemic, iatrogenic and epidemic, all of them associated with the human herpesvirus 8. We report a rare case of Kaposi sarcoma in an elderly immunodepressed female patient, not related to the acquired immunodeficiency syndrome, that evolved fatally in five months, since the appearance of hematic necrotic bullous lesions which progressed with intense local exudation, dehydration, renal insufficiency and worsening of the clinical status, ending in death, caused by multiple organ failure.
\end{abstract}

Keywords: Sarcoma, Kaposi; herpesvirus 8 human; neoplasms.

\section{Introdução}

O sarcoma de Kaposi (SK) foi descrito pela primeira vez em 1872 por Moritz Kaposi como "sarcoma hiperpigmentado múltiplo idiopático". Trata-se de uma neoplasia angioproliferativa maligna multicêntrica caracterizada sob o ponto de vista macroscópico pelo desenvolvimento de tumores vinhosos frequentemente elevados. Na maioria das vezes esses tumores restringem-se à pele e ao tecido subcutâneo, mas podem cursar comprometimento visceral amplamente disseminado. A análise microscópica caracteriza-se pela presença de canais revestidos por endotélio e espaços vasculares associados a agregados de células fusiformes de variados tamanhos.
Existem quatro variantes clínico-epidemiológicas conhecidas que possuem as mesmas características histológicas e parecem estar associadas à infecção pelo herpes vírus humano tipo 8 (HHV8, inglês human herpesvirus 8), segundo classificação descrita por Stebbing et al. em 2003 que classificam as manifestações clínicas de acordo com sua apresentação ${ }^{1,2}$ :

1. Clássico ou esporádico (mais prevalente na América do Norte, em descendentes de judeus do leste europeu e de povos do Mediterrâneo): mais frequente em homens idosos.

2. Africano/endêmico (principalmente regiões ao Sul do Saara): mais frequente em crianças e adultos jovens negros.

Hospital e Maternidade São Luiz (HMSL), São Paulo (SP), Brasil.

${ }^{1}$ Médico Chefe do Serviço de Cirurgia Vascular do Hospital e Maternidade São Luiz (HMSL), São Paulo (SP), Brasil.

${ }^{2}$ Médico Cirurgião Vascular do HMSL, São Paulo (SP), Brasil.

${ }^{3}$ Aluna de Graduação do $10^{\circ}$ semestre do Curso de Medicina da Universidade Cidade de São Paulo (Unicid), São Paulo (SP), Brasil.

${ }^{4}$ Doutor em Cirurgia pela Escola Paulista de Medicina da Universidade Federal de São Paulo (Unifesp); Responsável pelo Serviço de Transplante e Cirurgia do Fígado do HMSL; Professor de

Habilidades Cirúrgicas da Unicid; Professor Titular e Coordenador da Disciplina de Cirurgia Geral da Universidade de Santo Amaro (Unisa), São Paulo (SP), Brasil.

Não fora declarados conflitos de interesse associados à publicação deste artigo.

Submetido em: 31.07.2009 Aceito em: 26.07.2010

J Vasc Bras. 2010;9(4):261-265. 
3. Iatrogênico/imunossupressão: mais frequente em pacientes transplantados ou em uso de imunossupressores.

4. Epidêmico/associado à infecção pelo vírus da imunodeficiência humana adquirida (HIV): mais frequente em homens adultos jovens homossexuais e bissexuais ${ }^{2-4}$.

As lesões são mediadas por citocinas inflamatórias e fatores angiogênicos, que são desencadeados ou amplificados com a infecção pelo HHV8, frequentemente chamado como herpes vírus associado ao sarcoma de Kaposi (KSHV, do inglês Kaposi's sarcoma-associated herpevirus). Seu genoma decodifica proteínas envolvidas na proliferação celular, funções antiapoptóticas e inflamação ${ }^{5}$.

Quando associada ao HIV, apresenta-se de forma mais agressiva e aparece como o primeiro sintoma da síndrome da imunodeficiência adquirida (SIDA).

\section{Objetivo}

O objetivo deste relato foi apresentar um caso raro de SK em paciente imunossuprimida, não relacionado à SIDA, e realizar breve revisão de literatura.

\section{Descrição do caso}

Paciente do sexo feminino, 88 anos, brasileira, de descendência portuguesa, portadora de doença de Alzheimer e leucemia linfocítica crônica (LLC). Em fevereiro de 2007, deu entrada no pronto socorro do Hospital e Maternidade São Luiz (HMSL) devido a plaquetopenia e sangramento digestivo, quando foi firmado o diagnóstico de LLC por meio de biópsia de medula óssea.

Em julho de 2007, foi novamente atendida no Pronto Socorro do HMSL, devido a trombose venosa profunda

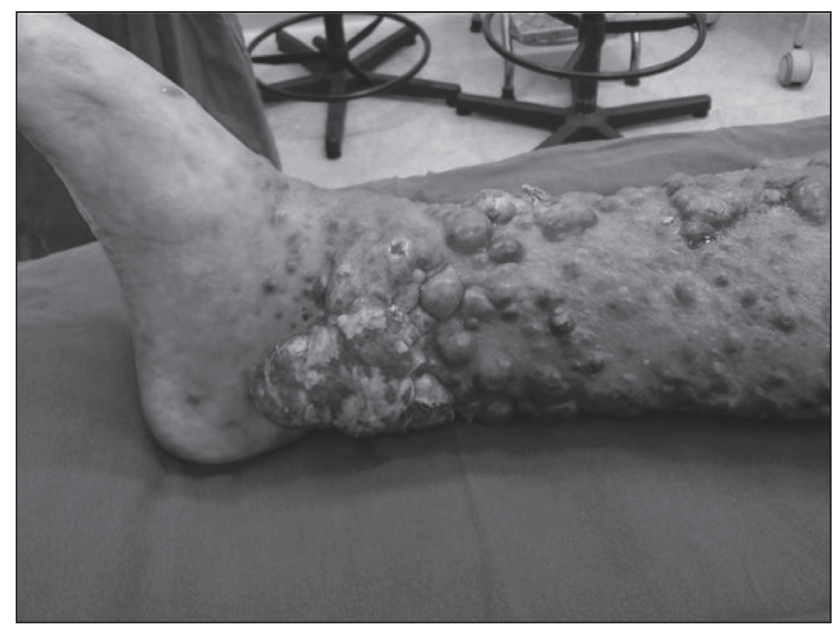

Figura 1 - Aspecto das lesões pré-operatórias
(TVP) fêmoro-poplítea esquerda, diagnosticada por meio de Eco Doppler colorido. Foi tratada com heparina de baixo peso molecular (HBPM) por seis dias, seguida de anticoagulação oral (warfarina) mantida por três meses, quando iniciou quadro grave de lesões bolhosas com conteúdo hemático nos membros inferiores (MMII), mais acentuados em pernas e pés. Nesse período, permaneceu internada na unidade de terapia intensiva (UTI) evoluindo satisfatoriamente e após a alta apresentou quadros repetidos de petéquias disseminadas nos MMII e nos membros superiores, necessitando de transfusão de plaquetas que resultou na remissão das complicações hemorrágicas. Foi suspensa a anticoagulação oral e a paciente foi encaminhada ao grupo de curativos do HMSL para tratamento das lesões bolhosas rotas.

Em outubro e novembro de 2007 apresentou dois episódios de erisipela nos MMII, sendo internada para tratamento com penicilina cristalina, 30 milhões U/dia, durante 7 dias e desbridamento de áreas de necrose e das lesões bolhosas hemáticas (Figuras 1 e 2). Após a cirurgia, foi prescrito o uso de warfarina, $5 \mathrm{mg} / \mathrm{dia}$, controlado com coagulograma, mantendo o controle do INR (razão/índice normalizado internacional) entre 2,0 e 3,0.

O material coletado durante o ato cirúrgico foi enviado para exame anatomopatológico cujo resultado indicou a presença de SK com ulceração, em estágio nodular. O material analisado era de consistência friável aos cortes, constituído por tecido hemorrágico. A análise histológica demonstrou agregados de células fusiformes, angiogênese, canais revestidos por endotélio, fibrina e áreas de hemorragia (Figura 3). A sorologia para HIV foi negativa e para o HHV8, positiva.

A paciente recebeu alta hospitalar em novembro de 2007 e foi encaminhada à radioterapia com o objetivo de controle local da doença.

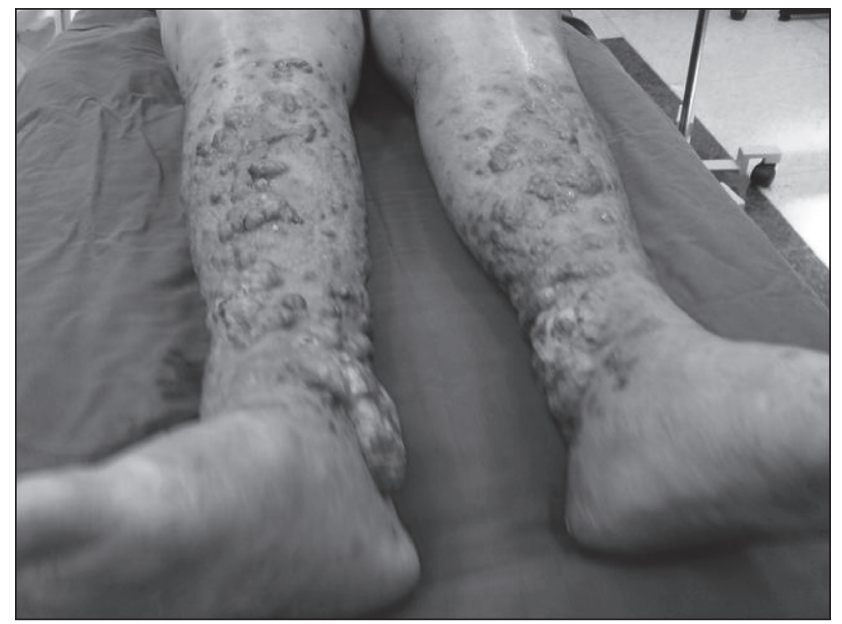

Figura 2 - Aspecto das lesões pré-operatórias 

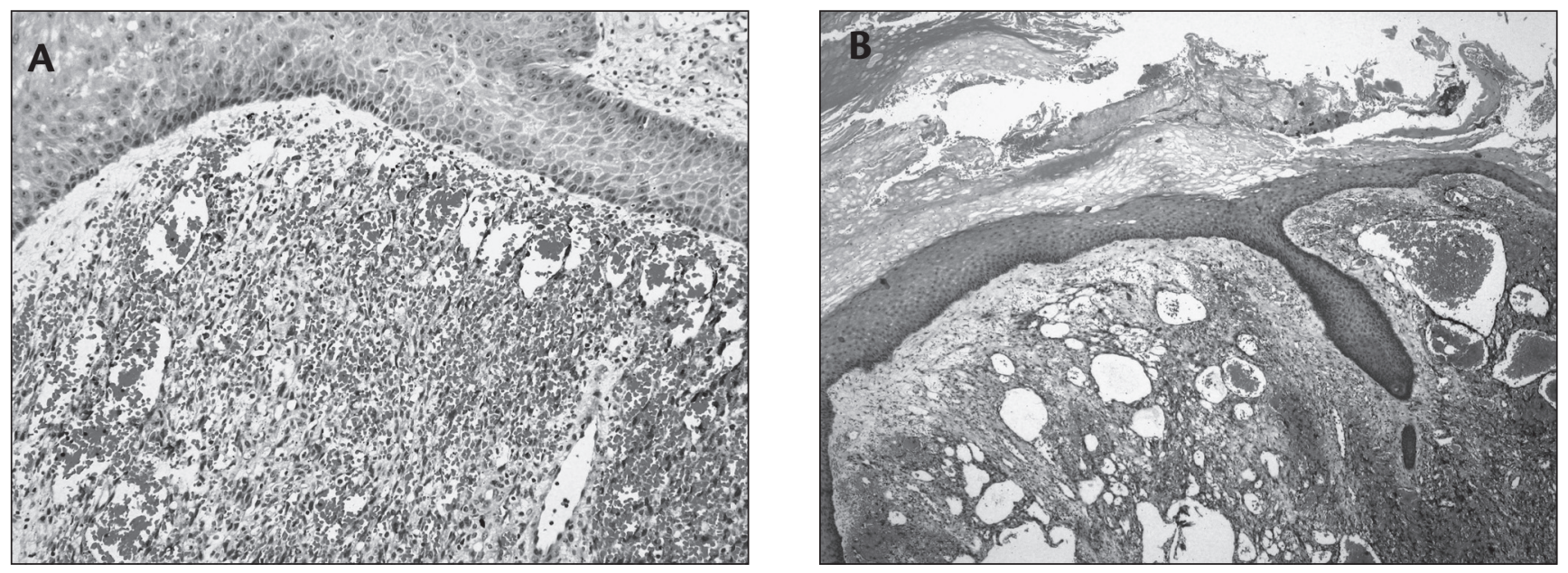

Figura 3 - (A e B) Histologia das lesões - sarcoma de Kaposi em estágio nodular

Aproximadamente um mês após a alta, aconteceram recidivas das necroses de pele e tecido celular subcutâneo nas regiões maleolares mediais com intensa exsudação local. Houve piora notável do quadro surgindo desidratação grave, insuficiência renal do tipo pré-renal, agravando-se o estado geral. A paciente evoluiu para óbito em razão de falência de múltiplos órgãos no dia 25 de dezembro de 2007.

\section{Discussão}

Diversos fatores são atribuídos a uma possível etiologia do SK, dentre eles: fator de crescimento endotelial, expressão oncogênica e predisposição genética associados a possíveis cofatores ambientais ${ }^{6}$; entretanto, sua etiologia ainda permanece obscura. Pesquisas apontam a existência de um agente transmissor como causa do SK, quer seja ligado à infecção pelo HIV ou não 5 .

Segundo Friedman-Kein et al. ${ }^{4}$ o SK era antigamente conhecido como uma doença muito rara que, entretanto, se tornou epidêmica entre homossexuais do sexo masculino, os quais são mais vulneráveis às condições que facilitam a transmissão do HIV, assim como do agente causador do SK. A imunossupressão, induzida pelo HIV em hospedeiros do agente etiológico, promove o desenvolvimento do SK e pode ser a primeira manifestação da SIDA.

A incidência da doença é maior em pacientes nos extremos etários, relacionada provavelmente à baixa imunidade, mas quando relacionados ao HIV, são pouco frequentes em crianças, ao contrário da forma endêmica (africana subequatoriana). Homens são mais afetados que mulheres, com uma proporção de 15:1 $1^{7-9}$. A incidência anual é de 0,02 a $0,06 \%$ de todos os tumores malignos ${ }^{7}$. O SK raramente compromete heterossexuais americanos ou europeus, mas ocorre com frequência em heterossexuais da África ou do Caribe $^{10}$.

A transmissão sexual pelo HHV8 predomina nos países desenvolvidos, principalmente relacionadas ao coito anal e ao número elevado de parceiros sexuais. A infecção pode ocorrer também durante o parto ou via transplacentária em áreas endêmicas. No entanto, foram relatados casos em crianças e adolescentes nessas áreas, sugerindo outra forma de transmissão que não a sexual. Não há consenso sobre a etiologia e via da transmissão do vírus; entretanto, o herpes vírus relacionado ao SK foi encontrado com muita frequência na saliva e no sêmen de pacientes infectados ${ }^{11,12}$.

O SK tem início em um contexto de desregulação imune caracterizada pela ativação de células T CD8+ e produção de citocinas estimuladas por células Th1 que induzem a ativação de células endoteliais, as quais promovem a adesão e o extravasamento de linfomonócitos, produção de células fusiformes e angiogênese. Esse fenômeno é desencadeado ou amplificado pela infecção pelo HHV8, que, por sua vez, é reativado por essas mesmas citocinas 5 .

A disseminação do HHV8 é favorecida pela desregulação e evasão imune pelo agente viral, o que torna difícil eliminar o vírus efetivamente, mas paradoxalmente, exacerba o processo reacional. As células circulantes infectadas pelo vírus são então recrutadas para os tecidos, onde desencadeiam as lesões 5 .

Safai et al. avaliaram pacientes com SK relacionado à SIDA sem infecção oportunista e observaram que a sobrevida foi de 28 meses a partir do diagnóstico para $80 \%$ dos pacientes, enquanto em pacientes com infecção oportunista associada, esse valor foi de aproximadamente 6 meses $^{13}$. O tumor pode manter-se estável e sem repercussões significativas ou progredir, o que ocorre em aproximadamente 
metade dos pacientes, que evoluem com envolvimento cutâneo e visceral ${ }^{14}$.

No caso em discussão, a paciente evoluiu rapidamente para óbito, em um período de cinco meses desde o aparecimento das primeiras lesões em MMII- mesmo não sendo portadora do HIV- e de suas infecções oportunistas, além de não apresentar a manifestação visceral do SK, o que indica maior gravidade da doença, representando uma forma atípica de sua manifestação.

O diagnóstico diferencial deve ser feito com linfoma cutâneo, hemangioma hemosiderótico, linfangioendotelioma benigno, angiossarcoma cutâneo, hemangioendotelioma de células fusiformes e angiolipoma. As lesões cutâneas induzidas pela heparina e warfarina (complicações raras desses anticoagulantes) também fazem parte desse grupo $^{2}$ e, nesse caso, fizeram parte do diagnóstico diferencial da paciente, uma vez que esta recebeu terapia anticoagulante devido à TVP.

Neste relato de caso buscamos enfatizar as circunstâncias atípicas nas quais o SK se desenvolveu. A paciente, brasileira com descendência portuguesa, não se enquadrava perfeitamente em nenhuma das quatro classificações clínico-epidemiológicas da doença. Geograficamente, a presença do SK clássico predomina em homens de regiões do Mediterrâneo, Leste europeu e América do Norte, enquanto o endêmico, nos povos da África, em especial homens jovens e crianças.

O SK epidêmico está estritamente relacionado a pacientes soropositivos para HIV, principalmente homossexuais jovens do sexo masculino. Em nosso relato, a paciente era idosa e soronegativa para HIV.

O SK iatrogênico e a imunossupressão ocorrem com maior frequência em pacientes receptores de transplantes, em especial o renal, ou ainda naqueles em terapia imunossupressora.

A única associação entre LLC e SK, além da imunossupressão, é a presença do complexo maior de histocompatibilidade (HLA-DR5), que foi descrito como tendo possível associação com SK em casos raros; porém, essa é apenas uma hipótese que ainda necessita de mais estudos para ser comprovada ${ }^{15,16}$.

\section{Conclusão}

A alta incidência em nosso meio de pacientes imunossuprimidos reforça a necessidade do reconhecimento precoce do SK no diagnóstico diferencial das lesões cutâneas. Esse diagnóstico em pacientes soronegativos para HIV é um desafio devido à sua baixa incidência e prevalência, sendo que frente a tais achados devem-se considerar as lesões cutâneas induzidas pela warfarina e pela heparina como parte do diagnóstico diferencial.

\section{Referências}

1. Stebbing J, Portsmouth S, Bower M. Insights into the molecular biology and sero-epidemiology of Kaposi's sarcoma. Curr Opin Infect Dis. 2003;16:25-31.

2. Fonseca BAL, Bollela, VR, da Justa P Neto. Sarcoma de Kaposi e síndrome da imunodeficiência adquirida: características desta associação, incluindo novos conceitos sobre patogênese e tratamento. Medicina, Ribeirão Preto. 1999;32:26-39.

3. Patrikidou A, Vahtsevanos K, Charalambidou M, Valeri RM, Xirou P, Antoniades K. Non-AIDS Kaposi's sarcoma in the head and neck area. Head Neck. 2009;31:260-8.

4. Friedman-Kien AE, Saltzman BR. Clinical manifestations of classical, endemic African, and epidemic AIDS-associated Kaposi's sarcoma. J Am Acad Dermatol. 1990;22:1237-50.

5. Ensoli B, Sgadari C, Barillari G, Sirianni MC, Stürzl M, Monini P. Biology of Kaposi's sarcoma. Eur J Cancer. 2001;37:1251-69.

6. Dourmishev LA, Dourmishev AL, Palmeri D, Schwartz RA, Lukac DM. Molecular genetics of Kaposi's sarcoma-associated herpesvirus (human herpesvirus-8) epidemiology and pathogenesis. Microbiol Mol Biol Rev. 2003;67:175-212.

7. Antman K, Chang Y. Kaposi's sarcoma. N Engl J Med. 2000;342:1027-38.

8. Wahman A, Melnick SL, Rhame FS, Potter JD. The epidemiology of classic, African, and immunosuppressed Kaposi's sarcoma. Epidemiol Rev. 1991;13:178-99.

9. Roye R, López M, Naranjo H, Zamora M. Sarcoma de Kaposi: Experiencia en el Departamento de Dermatología. Hospital Militar “Dr. Carlos Arvelo". Dermatología Venezolana. 2005;43:26-33.

10. Sitas F, Newton R. Kaposi's sarcoma in South Africa. J Natl Cancer Inst Monogr. 2001;28:1-4.

11. Leão JC, Hinrichsen SL, Freitas BL, Porter SR. Herpes vírus humano-8 e Sarcoma de Kaposi. Rev Assoc Med Bras. 1999;4555-62.

12. Pellett PE, Spira TJ, Bagasra O, et al. Multicenter comparison of PCR assays for detection of human herpesvirus 8 DNA in semen. J Clin Microbiol 1999;37:1298-301.

13. Safai B, Schwartz J). Kaposi's sarcoma and the acquired immunodeficiency syndrome. In: DeVita VT, Hellman S, Rosenberg SA. (Ed.): AIDS: etiology, diagnosis, treatment, and prevention. Philadelphia: Lippincott. 1997. p. 210-28.

14. Pantanowitz L, Mullen J, Dezube BJ. Primary Kaposi sarcoma of the subcutaneous tissue. World J Surg Oncol. 2008;6:94.

15. Strichman-Almashanu L, Weltfriend S, Gideoni O, FriedmanBirnbaum R, Pollack S. No significant association between HLA antigens and classic Kaposi sarcoma: molecular analysis of 49 Jewish patients. J Clin Immunol. 1995;15:205-9.

16. Wick MR. Kaposi's sarcoma unrelated to the acquired immunodeficiency syndrome. Curr Opin Oncol. 1991;3:377-83. 
Contato para correspondência: Francine Papaiordanou Rua Careaçú, 548 - Jardim França CEP: 02339-000 - São Paulo (SP), Brasil Tel: (11) 2952-9765/(11) 9939-0000/(11) 7715-3914 E-mail: francinepapaiordanou@hotmail.com

Contribuições dos autores: Apresentação e descrição do caso: MACJ e JAK Levantamento de literatura e redação do trabalho: FP, MAFR Jr Levantamento de literatura: MA Todos os autores leram e aprovaram a versão final do trabalho. 